\title{
Alfalfa Hay Supplementary Intake is Advancing Effect To Rumen Fermentation and Microbial Function of Gansu Alpine Fine Wool Sheep During Cold Season
}

Jia Jianlei ( $\square$ jiajianlei87@163.com )

Qinghai University https://orcid.org/0000-0001-5843-1709

Zhang Liping

Gansu Agricultural University

Guo Wujun

Gansu Agricultural University

Hou Guangtian

Xinjiang Academy of Animal Science

Wu Jianping

Gansu Academy of Agricultural Sciences

HAERALI SHABUER

Xinjiang Academy of Animal Science

Chen Qian

Qinghai University

\section{Research Article}

Keywords: Alfalfa Hay, Ruminal Fermentation, Ruminal microbes, Gansu Alpine Fine Wool Sheep, Cold Season

Posted Date: September 20th, 2021

DOl: https://doi.org/10.21203/rs.3.rs-803637/v1

License: (c) (1) This work is licensed under a Creative Commons Attribution 4.0 International License. Read Full License 


\section{Abstract}

Bodyweight loss and rumen microbial dysfunction of grazing sheep was a challenge for the sheep production industry during cold season, which were considered to correlated with under-roughagefeeding. The objective of our research was to assess the role of Alfalfa hay supplementary intake in roughage in ewes' rumen fermentation and microbial function. 120 ewes were allocated randomly into 4 groups, and were fed with different level of alfalfa hay, respectively. Individual ewes' bodyweight, blood biochemical indexes and rumen microbial characteristics were analyzed after the end of feeding trials. The results showed that alfalfa hay supplementary could significantly enhance sheep body weight, nitrogen components (Total-N, Soluble protein-N and Ammonia-N), blood biochemical indices (LDH, BUN and $\mathrm{CHO}$ ) and ruminal volatile fatty acids $(\mathrm{P}<0.05)$. Meantime, alfalfa hay supplementary increased the richness and diversity of ruminal fluid microbiota, and decreased ruminal fluid microbiota beta-diversity. The ruminal fluid microbiota of alfalfa hay supplementary feeding showed low immune pathway and high carbohydrate metabolism pathway. Overall, the study suggested that there was an increasing tendency of alfalfa-hay-supplementary group in 30\% Yellow Maize Silage $+70 \%$ Alfalfa Hay roughage in body weight, ruminal fermentation and microbial function, which improved GS performance through developing hay supplementary system during cold season.

\section{Introduction}

The Gansu alpine fine-wool sheep (GS) is the first cultivated breed of plateau type fine wool-sheep in Sunan plateau area, which is breed by means of crossbreeding and selective improvement from Xinjiang and Caucasus fine-wool sheep as male parents, and Tibetan sheep and Mongolian sheep as female parents(zhou WJ et al.2017). The Sunan plateau (Zhangye, Gansu) is known for its extreme harsh conditions,the characteristics is high altitude, low air oxygen and short forage growing season. GS grazed grassland all year round with traditional grazing management in Sunan plateau, however, long-lasting cold season and decline in nutritive value of pasture making it difficult to meet nutritional requirement for sheep, resulting in growth retardation, hypoimmunity and higher mortality rate(Deng KD et al.2018). During cold season (winter and early spring), there is a shortage of high-quality grass hay for GS, and it always struggle to maintain the normal physiological function. Previous researches demonstrated that there are positive effects of hay supplementary on sheep productive and reproductive performance, which can reduce body weight-lost, feeding costs, and increase economic efficiency(Tulu A et al.2018;Huang JQ et al.2017). Therefore, there is a big potential to improve GS performance through developing hay supplementary system in cold season.

Alfalfa has the advantages of rich nutrition and high quality, which is widely used in livestock production, and it is also praised as "the king of forage". Alfalfa hay is a good roughage resources for ruminants, which could improve nutrient digestibility, meat quality and production performance(Wang C et al.2019). There is great significance to promote animal health and improve animal production performance. Alfalfa was widely planted in Gansu Province, and Alfalfa hay, as high-quality roughage, had been well received in animal husbandry in Sunan plateau area. The diet nutritional value was affected by the feed intake, 
animal digestibility rate(Liu JH et al.2016). Many studies show that adding appropriate alfalfa hay to roughage could improve diet digestion, however, with the elevated proportion, the digestibility has a downward trend, which was resulting in a negative effect(Babiker EE et al.2016). Rumen was an important organ of nutrition digestion, absorption and metabolism, also a main barrier against harmful substances. The research showed that ruminal epithelium barriers was easy to be damaged by the influence of external factors, which leaded to microflora dysfunction, decrease the production performance(Fustini $\mathrm{M}$ et al.2016). Dietary interventions can improve production traits via changing gastrointestinal microflora abundance. The rumen microbiota is help to the host, including nutrient absorption, metabolism and developing the immune defense systems maintenance(Sun HZ et al.2016). Distinct microorganism (bacteria, archaea, fungi and protozoa) lived in the rumen with a symbiotic relationship of ruminant herbivore. These microbes could supply vitamins, protein and carbonhydtrate for host by secreting lytic enzymes available for the microbial fermentation. Additionally, rumen microorganisms improved both host organic immunity and resistance to invading pathogens(Cui ZH et al.2020).

The compositions of microbial communities of the ruminants were highly responsive to change in diet type, physiological status, and management strategy. Although several microbiome studies performed on ovine rumen, the adaption of rumen microbiome to changes in roughage was rarely reported. It is speculated that the feed rich in cellulose and hemicellulose is digested in rumen, and the nutrients are absorbed into organism through epithelium to provide energy for ruminants(Ozbayram EG et al.2017). Sheep could exhibit high dry matter, fiber digestion and efficient protein utilization when limiting by energy intake. Dietary protein and energy are often concomitantly limited in grazing GS during cold season. We questioned whether Alfalfa hay digestive rate would favor GS when offered the maintenance energy and protein intakes. Here, different levels of alfalfa hay were offered GS to simulate the supplement dietary intakes in the cold season to determine GS rumen biochemical indexes and microflora population. Collectively, our results shed new light on the effect of alfalfa hay supplement dietary on GS feeding.

\section{Material And Methods}

\section{Animals and Experimental Design}

The study was carried out in Yugur Autonomous County of Sunan, Gansu Province, China, which is situated at Qilian Mountain of northeastern Qinghai-Tibetan Plateau. This area is over $3000 \mathrm{~m}$ above the sea level and has a dry cold climate.

Gansu alpine fine wool ewes (aged 1.5-yr-old and $28.71 \pm 1.22 \mathrm{~kg}$ ) were housed at the Sunan herdsmen's professional cooperatives, Zhangye state, Gansu province, China. During the experimental period, all sheep were fed in intensively sheep-shed in supplementary feeding on different level hay, and the chemical composition of concentrate feed was the same in all groups. 120 ewes were allotted randomly into four groups (30 ewes/group), which were as follows: 100\% Yellow Maize Silage roughage group (A), 
70\% Yellow Maize Silage $+30 \%$ Alfalfa Hay roughage group (B), 30\% Yellow Maize Silage $+70 \%$ Alfalfa Hay roughage group (C) and $100 \%$ Alfalfa Hay roughage group (D). The dietary of each sheep consisted of $0.2 \mathrm{~kg}$ concentrate and $1.0 \mathrm{~kg}$ roughage (DM). Alfalfa hay were chopped into $1-2 \mathrm{~cm}$ length. The ingredients composition and nutritional level of Dietary were listed in Table 1. The experiment lasted for 100 days from 16th November 2017 to 23rd March 2018, where the first 10 days was adjustment period, followed by 90 days of data collection period.

Table 1

Dietary and Proximate Nutrition Content(DM)

\begin{tabular}{|lllll|}
\hline Maize & 50 & 50 & 50 & 50 \\
\hline Soybean Meal & 6.5 & 6.5 & 6.5 & 6.5 \\
\hline Cottonseed meal & 3 & 3 & 3 & 3 \\
\hline Rapeseed meal & 3.5 & 3.5 & 3.5 & 3.5 \\
\hline wheat bran & 3 & 3 & 3 & 3 \\
\hline Premix b & 4 & 4 & 4 & 4 \\
\hline Yellow Maize Silage & 30 & 21 & 9 & 0 \\
\hline Alfalfa Hay & 0 & 9 & 21 & 30 \\
\hline Nutritional level & & & & 11.45 \\
\hline ME(MJ/kg) a & 11.45 & 11.45 & 11.45 & 16.79 \\
\hline CP(\%DM) & 14.08 & 14.89 & 15.98 & \\
\hline
\end{tabular}

a Metabolizable energy (ME) was the calculated value, and others were the measured values.

b The premix provided the following per kg of dietary: VA 12000IU, VD 20 00IU, VE 30IU, Cu 12mg, Fe $64 \mathrm{mg}$, Mn 56mg, Zn 60mg, I 1.2mg, Se 0.4mg, Co 0.4mg.

\section{Bodyweight, Blood biochemical indices and Rumen fermentation measurement}

The GS were weighed at 1 day and 90 days of sample collection period by using platform scale before feeding in the morning.

Jugular blood $(10 \mathrm{~mL})$ was collected into heparinized vacutainer tubes and centrifuged at $2500 \mathrm{rpm}$ for 15 min. Plasma samples were stored at $-20^{\circ} \mathrm{C}$ for analysis of blood urea-N (BUN) concentration. Total protein (TP), Albumin (Alb), alanine aminotransferase (ALT), Aspartate aminotransferase (AST), triglyceride (TG), cholesterol (CHO), glucose (GLU), lactate dehydrogenase (LDH) was measured colorimetrically with auto analyzer (Aeroset, Abbot Toshiba, Japan) used commercially TaKaRa kits. 
The stomach tube was inserted into the rumen to collect rumen fluid. Approximately $50-100 \mathrm{ml}$ of rumen fluid was collected from each sheep, strained through 4 layers of cheesecloth and then the $\mathrm{pH}$ was determined immediately. The rumen fluid samples were aliquoted into $10 \mathrm{~mL}$ sterile tubes and then transferred to $\mathrm{a}-80^{\circ} \mathrm{C}$ ultracold storage freezer in the lab for further analysis. Ruminal TVFA, including acetic acid, propionic acid, butyric acid, analyzed by gas chromatography (TRACE GC 1300, Thermo Scientific, USA) using a capillary column (AT-FFAP: $30 \mathrm{~m}$ ). Ammonia-N, soluble protein-N and urea-N were determined by colorimetry (GENESYS 10S Vis, Thermo Scientific, USA): ammonia-N assay according to Hristov (2001); soluble protein-N assay according to Oosta (1978); and urea-N assay according to Marsh (1957).

\section{Rumen microbial characteristics}

The collected rumen fluid sampling was filtered with the 4-layer gauze. The liquid was filtered with a mixing fibroid membrane (aperture $0.45 \mu \mathrm{m}$ ) and filter membranes were stored at $-80^{\circ} \mathrm{C}$ for the extraction of DNA with the Magnetic Universal Genomic DNA Kit (TIANGEN, Beijing, China), following operational guidelines. TBS-380 (Turner BioSystems, USA) was employed to determine con-centration of extracted DNA while NanoDrop2000 (Thermo Fisher Scientific, USA) was used for assessing the purity of extracted DNA.

16S rRNA gene sequencing detection was outsourced to BIOMARKER (Beijing, China). Illumina HiSeq 2500 sequencing of $16 \mathrm{~S}$ rRNA gene was performed to characterize microbial diversity and community composition. The V3-V4 hypervariable region of the microbial 16S rRNA gene were amplified by PCR according to primers forward (5'-CCTACGGGNGGCWGCAG) and reverse (5'-GGACTACHVGGGTATCTAAT). The cycling protocol was $95^{\circ} \mathrm{C}$ for $2 \mathrm{~min} ; 35$ cycles at $95^{\circ} \mathrm{C}$ for $2 \mathrm{~min} ; 72^{\circ} \mathrm{C}$ for $30 \mathrm{~s}$; and $72^{\circ} \mathrm{C}$ for $5 \mathrm{~min}$.

The 16S rRNA analysis was performed by R software (version 3.1.2), QIIME software (version 1.9.1) and UPARSE software. According to the UPARSE pipeline, multiplexed reads were clustered into operational taxonomic units (OTUs) based on $97 \%$ sequence identity. The $16 \mathrm{~S}$ rRNA gene sequence was classified by RDP Classifier (version 2.2). Present figures were conducted using R package.

\section{Statistical analysis}

The results of the analysis were given as mean \pm SD and determined differences were shown according to level of hay supplementary. Duncan post hoc test was used to determine any significant differences between groups. Differences were considered as significant at $P<0.05$ and as a trend at $P<0.1$.

\section{Results}

\section{Bodyweight and blood biochemical indexes}

The initial weights, final weights of the GS $(\mathrm{kg})$ as well as daily body weight gain $(\mathrm{g} /$ day) of different alfalfa hay supplementary levels were presented in Table 2. Our results showed that the final weights and daily body weight gain of alfalfa-hay-supplementary groups (B, C and D group) were significantly higher 
than that of alfalfa-hay-free group (A group) $(P<0.05)$. There were no obvious differences among alfalfahay-supplementary groups in final weights $(P>0.05)$, and there was an increasing tendency of $30 \%$ Yellow Maize Silage $+70 \%$ Alfalfa Hay roughage group (C) in final weights, and daily body weight gain.

Table 2

Effect of Alfalfa Hay Supplementary on Body Weight

\begin{tabular}{|lllll|}
\hline Items & A & B & C & D \\
\hline Initial Weight $(\mathrm{Kg})$ & $28.03 \pm 0.72$ & $28.26 \pm 0.55$ & $27.97 \pm 0.95$ & $28.31 \pm 0.45$ \\
\hline Final Weight $(\mathrm{Kg})$ & $33.57 \pm 0.77^{\mathrm{a}}$ & $34.83 \pm 0.59^{\mathrm{b}}$ & $35.08 \pm 0.84^{\mathrm{b}}$ & $34.67 \pm 0.64^{\mathrm{b}}$ \\
\hline Average daily gain $(\mathrm{g} / \mathrm{d})$ & $61.56 \pm 4.43^{\mathrm{c}}$ & $73.00 \pm 4.95^{\mathrm{a}}$ & $78.89 \pm 4.03^{\mathrm{a}}$ & $70.37 \pm 3.25^{\mathrm{b}}$ \\
\hline
\end{tabular}

The blood biochemical indices obtained of different alfalfa hay supplementary levels were summarized in Tables 3. The BUN Value was above normal range, and others were within the normal range. LDH, BUN and $\mathrm{CHO}$ value of mixed-roughage groups ( $\mathrm{B}$ and $\mathrm{C}$ group) were significantly greater than singleroughage groups ( $A$ and $D$ group, $P<0.05$ ), and there were no significant differences in TP, Alb, AST, ALT, TG and GLU value among all groups $(P>0.05)$.

Table 3

Alfalfa Hay Supplementary on Blood biochemical indices

\begin{tabular}{|llllll|}
\hline Items & A & B & C & D & $\begin{array}{l}\text { Normal } \\
\text { Range }\end{array}$ \\
\hline TP g/L & $62.25 \pm 0.75$ & $63.25 \pm 1.42$ & $65.67 \pm 1.55$ & $63.28 \pm 1.18$ & $47.30-78.03$ \\
\hline Alb g/L & $32.33 \pm 0.33$ & $32.25 \pm 0.48$ & $32.75 \pm 0.48$ & $32.42 \pm 0.51$ & $15.48-38.11$ \\
\hline AST U/L & $130.25 \pm 4.31$ & $132.67 \pm 4.06$ & $133.48 \pm 3.08$ & $129.81 \pm 4.11$ & $106.5-142.5$ \\
\hline ALT U/L & $30.25 \pm 1.85$ & $30.33 \pm 1.88$ & $30.85 \pm 2.14$ & $30.18 \pm 1.59$ & $19.5-34.8$ \\
\hline $\begin{array}{l}\text { BUN mmol/L } \\
\uparrow\end{array}$ & $7.21 \pm 0.15^{\mathrm{b}}$ & $7.41 \pm 0.24^{\mathrm{a}}$ & $7.45 \pm 0.06^{\mathrm{a}}$ & $7.25 \pm 0.17^{\mathrm{b}}$ & $2.9-7.3$ \\
\hline $\mathrm{TG} \mathrm{mmol} / \mathrm{L}$ & $0.23 \pm 0.02$ & $0.24 \pm 0.05$ & $0.26 \pm 0.01$ & $0.02 \pm 0.01$ & $0.14-1.09$ \\
\hline $\mathrm{CHO} \mathrm{mmol} / \mathrm{L}$ & $2.62 \pm 0.02^{\mathrm{b}}$ & $2.92 \pm 0.05^{\mathrm{a}}$ & $2.93 \pm 0.04^{\mathrm{a}}$ & $2.54 \pm 0.06^{\mathrm{b}}$ & $2.0-3.4$ \\
\hline $\mathrm{LDH} \mathrm{mmol} / \mathrm{L}$ & $286.00 \pm$ & $304.75 \pm$ & $303.00 \pm$ & $289.37 \pm$ & $233.3-341.5$ \\
\hline $\mathrm{GLU} \mathrm{mmol} / \mathrm{L}$ & $2.22 \pm 0.27$ & $2.30 \pm 0.08$ & $2.31 \pm 0.22$ & $2.31 \pm 0.17$ & $1.5-2.5$ \\
\hline
\end{tabular}




\section{Rumen fermentation}

The ruminal $\mathrm{pH}$ and Nitrogen composition of different alfalfa hay supplementary levels were listed in Table 4, Total-N and Soluble protein-N of alfalfa-hay-supplementary groups (B, C and D group) were significantly higher than that of alfalfa-hay-free group (A group) $(P<0.05)$, Ammonia-N of mixedroughage groups ( $B$ and $C$ group) were significantly greater than single-roughage groups ( $A$ and $D$ group, $P<0.05)$, there was no significant difference in ruminal $\mathrm{pH}$ and Urea-N among all groups $(P>0.05)$. The ruminal Volatile Fatty Acids (VFAs) of different alfalfa hay supplementary levels were listed in Table 5 , TVFA, Butyrate and Acetate/ Propionate of alfalfa-hay-supplementary groups (B, C and D group) were significantly higher than that of alfalfa-hay-free group (A group, $P<0.05$ ), Propionate of mixed-roughage groups ( $B$ and $C$ group) were significantly greater than single-roughage groups ( $A$ and $D$ group, $P<0.05$ ), there was no significant difference in Acetate between 4 groups $(P>0.05)$.

Table 4

Alfalfa Hay Supplementary on ruminal $\mathrm{pH}$ and nitrogenous components

\begin{tabular}{|llllll|}
\hline Items & $\mathbf{p H}$ & Ammonia-N & Urea-N & Total-N & Soluble protein-N \\
\hline A & $6.41 \pm 0.07$ & $20.79 \pm 0.15^{\mathrm{b}}$ & $1.09 \pm 0.05$ & $125.31 \pm 0.12^{\mathrm{b}}$ & $102.40 \pm 0.05^{\mathrm{b}}$ \\
\hline $\mathrm{B}$ & $6.45 \pm 0.83$ & $23.77 \pm 0.48^{\mathrm{a}}$ & $1.17 \pm 0.09$ & $131.94 \pm 0.33^{\mathrm{a}}$ & $108.21 \pm 0.25^{\mathrm{a}}$ \\
\hline C & $6.44 \pm 0.11$ & $24.24 \pm 0.70^{\mathrm{a}}$ & $1.15 \pm 0.04$ & $134.29 \pm 0.56^{\mathrm{a}}$ & $112.65 \pm 0.92^{\mathrm{a}}$ \\
\hline D & $6.43 \pm 0.58$ & $21.23 \pm 0.71^{\mathrm{b}}$ & $1.11 \pm 0.03$ & $129.54 \pm 1.23^{\mathrm{a}}$ & $106.37 \pm 0.73^{\mathrm{a}}$ \\
\hline
\end{tabular}

Table 5

Effect of level of hay intake on ruminal VFAs

\begin{tabular}{|llllll|}
\hline Items & TVFA(mmol/L) & Acetate(\%) & Propionate(\%) & Butyrate(\%) & Acetate/ Propionate \\
\hline A & $48.71 \pm 3.16^{\mathrm{b}}$ & $27.84 \pm 2.28$ & $12.93 \pm 0.62^{\mathrm{c}}$ & $4.80 \pm 0.26^{\mathrm{b}}$ & $2.15 \pm 0.08^{\mathrm{a}}$ \\
\hline B & $57.84 \pm 2.40^{\mathrm{a}}$ & $27.23 \pm 4.03$ & $20.30 \pm 0.74^{\mathrm{a}}$ & $7.59 \pm 0.50^{\mathrm{a}}$ & $1.39 \pm 0.11^{\mathrm{c}}$ \\
\hline C & $59.49 \pm 3.28^{\mathrm{a}}$ & $29.90 \pm 2.49$ & $21.39 \pm 0.91^{\mathrm{a}}$ & $7.34 \pm 0.78^{\mathrm{a}}$ & $1.34 \pm 0.12^{\mathrm{c}}$ \\
\hline D & $55.97 \pm 1.96^{\mathrm{a}}$ & $28.46 \pm 3.15$ & $17.29 \pm 0.54^{\mathrm{b}}$ & $7.64 \pm 0.38^{\mathrm{a}}$ & $1.64 \pm 0.13^{\mathrm{b}}$ \\
\hline
\end{tabular}

\section{Rumen microbial community and function}

After filtering out low-quality reads and chimeras of Illumina sequenced reads, we obtained a total of 996 032 clean tags high-quality sequences. The number of sequences for 24 sample ranged from 887134 to 1011715 . The Good's coverage was in the range of 0.9818 to 0.9867 . The remaining high-quality 
sequences were clustered into OTUs according to $97 \%$ similarity level by UPARSE software. All detected OTUs were 24 432and the averaged value of OTUs for each sample was 687, which mapped to 21 phyla, 41 classes, 89 orders, 147 families, 297 genera and 324 species (Fig. 1). The top 10 relative ruminal fluid microbiota abundances at the genus level are presented in Fig. 2. Ruminococcus, Ruminococcaceae and Prevotella were observed as the predominant phyla in ruminal fluid microbiota, followed by

Christensenellaceae, Quinella, Rikenellaceae and Butyrivibrio. The relative abundances of Ruminococcus, Christensenellaceae, Ruminococcaceae and Prevotella accounted for more than $1 \%$ of the total microbiome. For $30 \%$ Yellow Maize Silage $+70 \%$ Alfalfa Hay roughage group (C), the relative abundance of beneficial microorganisms was significantly increased $(P<0.05)$ compared with other groups $(P<$ 0.05). Ruminococcus and Quinella of mixed-roughage groups (B and $C$ group) were significantly greater than single-roughage groups ( $A$ and $D$ group, $P<0.05$ ).

The alpha diversity was estimated through the diversity index (Shannon and Simpson) and richness estimate (Chao1 and ACE). As can be seen in Table 6, the richness estimate (Simpson, ACE and Chao1) increased significantly for mixed-roughage groups ( $B$ and $C$ group) compared to single-roughage groups ( $A$ and $D$ group), whereas the Shannon indices were significantly lower than mixed-roughage groups ( $B$ and $C$ group, $P<0.05)$. 30\% Yellow Maize Silage $+70 \%$ Alfalfa Hay roughage group (C) almost showed significant enhancement in the alpha-diversity of ruminal fluid microflora than other groups, this indicated that $70 \%$ Alfalfa Hay roughage feeding increased the richness and diversity of ruminal fluid microbiota. Furthermore, the differences in the microbial beta-diversity between the different feeding groups were evaluated based on binary jaccard distances (Fig. 3). The mixed-roughage groups (B and C group) showed lower ruminal fluid microbiota beta-diversity, which indicated their higher microbiota stability and lower dispersion. Principal co-ordinates analysis (PCoA) using the weighted unifrac similarity method revealed that the PC1 and PC2 explained $49.12 \%$ and $12.10 \%$ of the variation between the samples, respectively, it indicated that ruminal fluid samples from different groups formed different clusters in the ordination space (Fig. 4).

Table 6

Alpha diversity of ruminal fluid samples

\begin{tabular}{|lllll|}
\hline Items & A & B & C & D \\
\hline Shannon & $4.13 \pm 0.28^{\mathrm{b}}$ & $4.79 \pm 0.15^{\mathrm{a}}$ & $4.73 \pm 0.21^{\mathrm{a}}$ & $4.71 \pm 0.29^{\mathrm{a}}$ \\
\hline Simpson & $0.064 \pm 0.019^{\mathrm{a}}$ & $0.026 \pm 0.003^{\mathrm{b}}$ & $0.027 \pm 0.08^{\mathrm{b}}$ & $0.032 \pm 0.007^{\mathrm{b}}$ \\
\hline ACE & $878.87 \pm 3.47^{\mathrm{a}}$ & $734.79 \pm 6.29^{\mathrm{b}}$ & $758.33 \pm 9.99^{\mathrm{b}}$ & $747.25 \pm 5.35^{\mathrm{b}}$ \\
\hline Chao1 & $873.69 \pm 15.07^{\mathrm{a}}$ & $749.93 \pm 17.54^{\mathrm{b}}$ & $702.43 \pm 17.47^{\mathrm{b}}$ & $747.99 \pm 16.33^{\mathrm{b}}$ \\
\hline Coverage/\% & 98.67 & 98.18 & 98.33 & 98.36 \\
\hline
\end{tabular}




\section{Microbial community structure}

We performed LEfSe analyses to identify the significance of different taxa (relative abundance $>1 \%$ ) among 4 groups, and LDA results from the LEfSe analysis were showed in Fig. 5. In A group, we found that Bacilli, Lactobacillales, Firmicutes, Streptococcaceae and Streptococcus were significantly abundant taxa. In B group, Gammaproteobacteria, Escherichia_Shigella, Negativicutes, Selenomonadales, Veillonellaceae and Prevotellaceae were significantly abundant taxa. In C group, Buchnera, Alphaproteobacteria, Rickettsiales, Rickettsiaceae and Rickettsia were significantly abundant taxa. In D group, Prevotella_7, Bacteroidales, Bacteroidia, Bacteroidetes, Megasphaera and Pseudomonadales were significantly abundant taxa. To investigate the functional capacity of the ruminal fluid microbiota communities, PICRUSt was used to further analysis the KEGG pathway compositions (Fig. 6). The results showed that the second level KEGG pathway of Amino acid transport and metabolism, Carbohydrate transport and metabolism, Cell cycle control, Cell motility, Cytoskeleton, Energy production and metabolism were enriched.

\section{Discussion}

Rumen is an important part of the digestion, absorption, and metabolism of nutrients, and acts as an important barrier against the harmful substances, thereby, playing an important role in the sheep health(Sun XZ et al.2020). The ruminant need intake 30\%-70\% dietary roughage to maintain normal rumen function and gastrointestinal microflora environment. Many researchers have reported that additional hay feeds can elicit a response in terms of reduced weight loss, increased growth and production in grazing sheep farming system(Scocco $P$ et al.2016). The fine-wool ewes supplemented with concentrate feed or hay lost less weight over winter than the hay supplementary feed systems have been widely used to balance nutrition of ruminants fed low quality forage-based diets on confinedness(He B et al.2019). In our studies, 30\% Yellow Maize Silage + 70\% Alfalfa hay supplementary intake could be useful to increase sheep serum chemistry values, it was in accordance with earlier reports for grazing sheep with supplemented hay in cold season.

Modern hay supplementary intake pattern changed the feedstuff residing time in sheep rumen and improved the amount of carbohydrate and microbial fermentation level(Belanche A et al.2019;Hristov AN et al.2001;Oosta GM et al.1978). Basically, Ruminal pH depends mainly on the balance of VFAs production and buffer secretion, which are used to reflect rumen natural activities status(Marsh WH et al.1957). Our research showed that the pH value of GS was between 6.41-6.45, which was within the optimal range. It indicated that our sheep dietary could maintain the stability of rumen environment, and ensure the degradation of roughage via rumen microorganisms. Ammonia- $\mathrm{N}$ is the most important $\mathrm{N}$ source for microbial protein synthesis in the rumen(Zhou XL et al.2018;Wishart $\mathrm{H}$ et al.2018). Ammonia$\mathrm{N}$, Total-N and Soluble protein- $\mathrm{N}$ were observed greater in alfalfa-hay-supplementary groups (B, C and D group) than alfalfa-hay-free group (A group), indicating the larger $\mathrm{N}$ resources for microbial growth in Alfalfa hay supplementary intake. In the present study, a greater efficiency of urea recycling was observed 
in $30 \%$ Yellow Maize Silage $+70 \%$ Alfalfa Hay roughage group (C), which helps these animals to survive under poor dietary condition of the Sunan Plateau.

As far as we know, VFAs originated from carbohydrates via hydrolysis by ruminal microbes. The observed negative relationship between ruminal $\mathrm{pH}$ and VFAs concentration in the present study had been reported in several publications(Guo W et al.2020). The greater ruminal TVFA in alfalfa-hay-supplementary groups ( $B, C$ and $D$ group) than alfalfa-hay-free group (A group) implied that there was more energy absorption for alfalfa-hay-supplementary than alfalfa-hay-free when consuming with the same energy intakes. The changed tendencies in molar proportions of propionate and butyrate reflected the shift in VFA-producing pathways and microbial populations(Huang XD et al.2020). The predominant ruminal microbes would be fibrolytic microbes(Zhang ZG et al.2016). The decreased molar proportion of propionate and butyrate with a decrease first and then increase in alfalfa hay intake most likely resulted from the stimulated activity of fibrolytic microbes for TVFAs incorporation in microbial protein synthesis(Colmenero $\mathrm{JJ}$,Broderick GA.2006). Serum BUN level is associated with protein uptake, the alfalfa hay was rich in protein, according to our results, BUN activities not only increased in mixed-roughage groups (B and $C$ group), but also its level increased above the normal range during cold season. The increased BUN levels prove the high protein uptake in mixed-roughage groups ( $B$ and $C$ group) than single-roughage groups supplementary feed groups. There is evidence that $\mathrm{CHO}$ deficiencies are common in grazing animals. In previous study, $\mathrm{CHO}$ levels were found below $2.0 \mathrm{mmol} / \mathrm{L}$ in grazing $\mathrm{GS}$, and increased $\mathrm{CHO}$ activities in present study can be depend on alfalfa hay supplementary intake, which increased Cholesterol Oxidase, then compensation of the decreased $\mathrm{CHO}$ levels. $\mathrm{LDH}$ is an important enzyme in glycolysis, taking together our results associated with carbohydrate metabolism that $\mathrm{LDH}$ of mixed-roughage groups (B and $C$ group) were significantly greater than single-roughage groups ( $A$ and $D$ group),the reasons for this phenomenon that mixed-roughage supplementary in sheep dietary might be increased carbohydrate metabolism.

Ruminant rumen encompass a large number of complex and diverse microorganisms, which are critical for the body metabolism and the homeostasis of ruminal barrier by regulating the transformation of nutrients' uptake(Yang XX et al.2019;Xue D et al.2017). A number of studies have shown that lacking hay supplementary intake ruminant had impaired ruminal barrier function, which enhanced the transferring of toxic metabolic products from the rumen into blood circulation via ruminal microflora dysfunction and microbial translocation, causing an inflammatory response and tissue dysfunction( $\mathrm{Li} \mathrm{C}$ et al.2017;Rahman MK et al.2018;Sunny NE et al.2006). Therefore, the dynamic equilibrium of the structure and function of rumen microbiota contributes to explore underlying mechanism of sheep rumen digestive function in GS alfalfa hay supplementary feeding system(Ji SK et al.2017). The 16S rRNA microbial sequencing technology is an important method to explore the functions and activities of the ruminant's gastrointestinal microbiota(Xue D et al.2017). Ruminant gastrointestinal microorganisms adjusted their own protein synthesis and gene expression to assist in the digestion and synthesis of nutrients(Zhang LH et al.2019;Cao DX et al.2019; Wang JB et a.2015;Ma $L$ et al.2019). The hay supplementary feeding has been shown to be the important factors that affect the gastrointestinal microorganisms(Kim M et al.2019;Mamiko K et al.2017).Our results showed that Ruminococcus were the dominant microbiota in 
alfalfa hay supplementary intake trials. The abundance of Ruminococcus changed, which led to the changes of fiber digestive ability and the formation of short chain fatty acids (SCFAs) in different alfalfa hay supplementary trials. It is well-known that the SCFAs provides energy, enhance digestion, and regulates the metabolism in ruminal epithelial cells by binding to $\mathrm{G}$ protein-coupled receptors of SCFAs. Meanwhile, the ruminal epithelial cells proliferated and differentiated by inhibiting the histone deacetylase. The expression of low immune pathway and high carbohydrate metabolism pathway genes appeared to be distinguishing features of the alfalfa-hay-supplementary groups rumen microorganisms. Our study suggests that the $30 \%$ Yellow Maize Silage $+70 \%$ Alfalfa Hay roughage group (C) had significant effects on the microbial diversity and Energy production and metabolism of GS rumen, and this research may help to explain the better adaptability of Gansu fine-wool sheep to the harsh plateau environment.

\section{Declarations}

Author contribution All authors have contributed substantially to the work and approved the fnal manuscript.

Acknowledgements The authors are grateful to all the participants who took part in this study.

Funding This work was supported by Public Sector (Agriculture) Special Project (Grazing Cattle and Sheep Balanced Nutrition Needed for Scientific Research and Demonstration) [201303062], Joint Project of System of Industrial Technology for Fluff Sheep and Grazing Ecology Position Scientists [CARS-4009B] and Qinghai Natural Science Foundation [2020-ZJ-735].

Data Availability All data and materials used to support the findings of this study have been included in this publication.

Ethical approval This study was approved by the Institutional Animal Care and Use Committee of Gansu Agriculture University (Protocol 20170407-6). All research involving animals was conducted according to either the Canadian Council on Animal Care (CCAC) guidelines or the Guide for the Care and Use of Laboratory Animals (8th edition, National Academies Press).

Conflict of Interest the Authors declare no conflict of interest.

\section{References}

1. Zhou WJ, Mi JD, Degen AA, Ding LM, Guo XS, Shang ZH, Wang WW, Long RJ: Urinary purine derivatives excretion, rumen microbial nitrogen synthesis and the efficiency of utilization of recycled urea in Tibetan and fine-wool sheep. Anim Feed Sci Tech, 222: 24-31, 2017. DOI:

10.1016/j.anifeedsci.2017.03.005

2. Deng KD, Xiao Y, Ma T, Tu Y, Diao QY, Chen YH, Jiang JJ: Ruminal fermentation, nutrient metabolism, and methane emissions of sheep in response to dietary supplementation with Bacillus licheniformis. 
Anim Feed Sci Tech, 241: 38-44, 2018. DOI: 10.1016/j.anifeedsci.2018.04.014

3. Tulu A, Khushi Diriba YR, Scholar GC: Supplementary value of two Lablab purpureus cultivars and concentrate mixture to natural grass hay basal diet based on feed intake, digestibility, growth performance and net return of Horro sheep. Liv Produc Sci, 9(6): 140-150, 2018. DOI: 10.5897/IJLP2014.0223

4. Huang JQ, Li YJ, Luo YZ: Bacterial community in the rumen of Tibetan sheep and Gansu alpine finewool sheep grazing on the Qinghai-Tibetan Plateau, China. J Gen Appl Microbiol, 63(2):122-130, 2017.DOI: $10.2323 /$ jgam.2016.08.003

5. Wang C, He LW, Xing YQ, Zhou W, Yang FY, Chen XY, Zhang Q: Fermentation quality and microbial community of alfalfa and stylo silage mixed with Moringa oleifera leaves. Bioresource Technol, 284: 240-247, 2019. DOI: 10.1016/j.biortech.2019.03.129

6. Liu JH, Zhang ML, Xue CX, Zhu WY, Miao SY: Characterization and comparison of the temporal dynamics of ruminal bacterial microbiota colonizing rice straw and alfalfa hay within ruminants. $J$ Dairy Sci, 99(12): 9668-9681, 2016. DOI: 10.3168/jds.2016-11398

7. Babiker EE, Juhaimi FAJ, Ghafoor K, Abdoun KA: Comparative study on feeding value of Moringa leaves as a partial replacement for alfalfa hay in ewes and goats. Livest Sci, 195: 21-26, 2017. DOI: 10.1016/j.livsci.2016.11.010

8. Fustini M, Palmonari A, Canestrari G, Bonfante E, Mammi L, Pacchioli MT, Sniffen GCJ, Grant RJ, Cotanch KW, Formigoni A: Effect of undigested neutral detergent fiber content of alfalfa hay on lactating dairy cows: Feeding behavior, fiber digestibility, and lactation performance. J Dairy Sci, 100(6): 4475-4483, 2017. DOI: 10.3168/jds.2016-12266

9. Sun HZ, Wang B, Wang JK, Liu HY, Liu JX: Biomarker and pathway analyses of urine metabolomics in dairy cows when corn stover replaces alfalfa hay. J Anim Sci Biotechno, 7: 49-56, 2016. DOI: 10.1186/s40104-016-0107-7.

10. Cui ZH, Wu SR, Li JL, Yang QE, Chai ST, Wang L, Wang X, Zhang XW, Liu SJ, Yao JH: Effect of Alfalfa Hay and Starter Feeding Intervention on Gastrointestinal Microbial Community, Growth and Immune Performance of Yak Calves. Front Microbiol, 11: 994-1014, 2020. DOI: 10.3389/fmicb.2020.00994

11. Ozbayram EG, Kleinsteuber S, Nikolausz M, Ince B, Ince O: Effect of bioaugmentation by cellulolytic bacteria enriched from sheep rumen on methane production from wheat straw. Anaerobe, 46: 122130, 2017. DOI: 10.1016/j.anaerobe.2017.03.013

12. Sun XZ, Chen A, David P, Hoskin SO, Luo DW: Sheep Rumen Fermentation Characteristics Affected by Feeding Frequency and Feeding Level When Fed Fresh Forage. Animals, 10(1): 7-16, 2020. DOI: 10.3390/ani10010007

13. Scocco P, Mercati F, Tardella FM, Catorci A: Increase of forage dryness induces differentiated anatomical response in the sheep rumen compartments. Microsc Res Techniq, 79(8): 738-743, 2016. DOI: $10.1002 /$ jemt.22692

14. He B, Jin SW, Cao JW, Mi L, Wang JK: Metatranscriptomics of the Hu sheep rumen microbiome reveals novel cellulases. Biotechnol Biofuels, 12: 153-167, 2019. DOI: 10.1186/s13068-019-1498-4 
15. Belanche A, Kingston-Smith AH, Griffith GE, Newbold CJ: A Multi-Kingdom Study Reveals the Plasticity of the Rumen Microbiota in Response to a Shift From Non-grazing to Grazing Diets in Sheep. Front Microbiol, 10: 122-139, 2019. DOI: 10.3389/fmicb.2019.00122

16. Hristov AN, Ivan M, Rode LM, McAllister TA: Fermentation characteristics and ruminal ciliate protozoal populations in cattle fed medium- or high-concentrate barley-based diets. J Anim Sci, 79(2): 515-524, 2001. DOI: 10.2527/2001.792515x

17. Oosta GM, Mathewson NS, Catravas GN: Optimization of Folin-Ciocalteu reagent concentration in an automated Lowry protein assay. Anal Biochem, 89(1): 31-34, 1978. DOI: 10.1016/00032697(78)90723-6

18. Marsh WH, Fingerhut B, Kirsch E: Determination of urea nitrogen with the diacetyl method and an automatic dialyzing apparatus. Am J Clin Pathol, 27(11): 239-246, 1957. DOI:

10.1093/ajcp/28.6_ts.681

19. Zhou XL, Wu XY, Liang CN, Guo X, Chu M, Wang HB: The complete mitochondrial genome of Sunan yak (Bos grunniens) and a phylogenetic study. Mitochondrlal Dna B, 4(1): 1053-1054, 2019. DOI: 10.1080/23802359.2018.1546149

20. Wishart H, Morgan-Davies C, Stott A, Wilson R, Waterhouse T: Liveweight loss associated with handling and weighing of grazing sheep. Small Ruminant Res, 153: 163-170, 2017. DOI: 10.1016/j.smallrumres.2017.06.013

21. Guo W, Wang WW, Bi SS, Long RJ, Ullah FM, Shafiq F, Zhou M, Zhang Y: Characterization of Anaerobic Rumen Fungal Community Composition in Yak, Tibetan Sheep and Small Tail Han Sheep Grazing on the Qinghai-Tibetan Plateau. Animals, 10:144-157, 2020. DOI:10.3390/ani10010144

22. Huang XD, Tan HY, Long RJ, Liang JB, Wright ADG: Comparison of methanogen diversity of yak (Bos grunniens) and cattle (Bos taurus) from the Qinghai-Tibetan plateau, China. Bmc Microbiol, 12: 237241, 2020. DOI:10.1186/1471-2180-12-237

23. Zhang ZG, Xu, DM, Wang L, Hao JJ, Wang JF, Zhou X, Wang WW, Qiu Q, Huang XD, Zhou JW, Long RJ, Zhao FQ, Shi P: Convergent evolution of rumen microbiomes in high-altitude mammals. Curr Biol, 26 (14): 1873-1879, 2016. DOI: 10.1016/j.cub.2016.05.012

24. Colmenero JJ, Broderick GA: Effect of dietary crude protein concentration on milk production and nitrogen utilization in lactating dairy cows. J Dairy Sci, 89(5): 1704-1712, 2006.

DOI:10.3168/jds.S0022-0302(06)72238-X

25. Yang XX, Dong QM, Chu H, Ding CX, Yu Y, Zhang CP, Zhang YF, Yang ZZ: Different responses of soil element contents and their stoichiometry (C:N:P) to yak grazing and Tibetan sheep grazing in an alpine grassland on the eastern Qinghai-Tibetan Plateau. Agr Ecosyst Environ, 285:106628, 2019. DOI: 10.1016/j.agee.2019.106628

26. Xue D, Chen H, Zhao XQ, Xu SX, Hu LY, Xu TW, Jiang L, Zhang W: Rumen prokaryotic communities of ruminants under different feeding paradigms on the Qinghai-Tibetan Plateau. Syst Appl Microbiol, 40: 227-236, 2017. DOI: 10.1016/j.syapm.2017.03.006 
27. Li C, Xue S, Zhao Q: Effect of licking molasses-urea block on weight gain, rumen fermentation, and the main microbe populations of grazing sheep during grass withering period. J Anim Sci, 95(4), 335, 2017. DOI: $10.2527 /$ asasann.2017.686

28. Rahman MK, Islam S, Islam A, Uddin MH, Hossain MB, Hassan MM, Islam A: Determination of hematological and serum biochemical reference values for indigenous sheep (Ovies aries) in Dhaka and Chittagong Districts of Bangladesh. Vet World, 11(8): 1089-1093, 2018. DOI:

10.14202/vetworld.2018.1089-1093

29. Sunny NE, Owens SL, Baldwin RL, El-Kadi SW, Kohn RA, Bequette BJ: Salvage of blood urea nitrogen in sheep is highly dependent on plasma urea concentration and efficiency of capture within the digestive tract. J Anim Sci, 85: 1006-1013, 2007. DOI: 10.2527/jas.2006-548

30. Ji SK, Zhang F, Sun YK, Deng KD, Wang B, Tu Y, Zhang NF, Jiang CG, Wang SQ, Diao QY: Influence of dietary slow-release urea on growth performance, organ development and serum biochemical parameters of mutton sheep. J Anim Physiol An N, 101(5): 964-973, 2017. DOI: 10.1111/jpn.12532.

31. Xue D, Chen H, Zhao XQ, Xu SX, Hu LY, Xu TW, Jiang L, Zhan W: Rumen prokaryotic communities of ruminants under different feeding paradigms on the Qinghai-Tibetan Plateau. Syst Appl Microbiol, 40: 227-236, 2017. DOI: 10.1016/j.syapm.2017.03.006

32. Zhang LH, Xiong J, Li JK, Waqas M, Gao X, Li K, Xie GP, Zhang JL, Mehmood K, Zhao SN, Wangdui B, Li JK: Characterization of the microbial community structure in intestinal segments of yak (Bos grunniens). Anaerobe, 61: 102-115, 2020. DOI: 10.1016/j.anaerobe.2019.102115

33. Cao DX, Wang SL, Wang R, Chai ST, Liu SJ, Hao LZ: Changes of $\beta$-carotene and retinol levels and BCO1 gene and protein expressions in yak tissues at different nutritional seasons. J Anim Feed Sci, 28:120-127, 2019. DOI: 10.22358/jafs/109953/2019

34. Wang JB, Zhang R, Zhang L, Wang CJ, Shao BP, Wang JL: Histomorphometric Adaptation of Yak (Bos grunniens) Abomasum to the Qinghai-Tibetan Plateau Environment. Int J Morphol, 33(2):764776, 2015. DOI:10.4067/S0717-950220150002000

35. Ma L, Xu SX, Liu HJ, Xu TW, Hu LY, Zhao N, Han XP, Zhang XL: Yak rumen microbial diversity at different forage growth stages of an alpine meadow on the Qinghai-Tibet Plateau. Peer J, 7:11-27, 2019. DOI: $10.7717 /$ peerj. 7645

36. Kim M, Park T, Yu ZT: Metagenomic investigation of gastrointestinal microbiome in cattle. Asian Austral J Anim, 30(11): 1515-1528, 2017. DOI: 10.5713/ajas.17.0544

37. Mamiko K, Daisuke M, Hideki K, Kamiyama K, Morikawa Y, Yokoi S, Kasuno K, Takahashi N, Taniguchi T, Iwano M: Short-chain fatty acids, GPR41 and GPR43 ligands, inhibit TNF-a-induced MCP-1 expression by modulating p38 and JNK signaling pathways in human renal cortical epithelial cells. Biochem Bioph Res Co, 486(2): 499-505, 2017. DOI: 10.1016/j.bbrc.2017.03.071

\section{Figures}




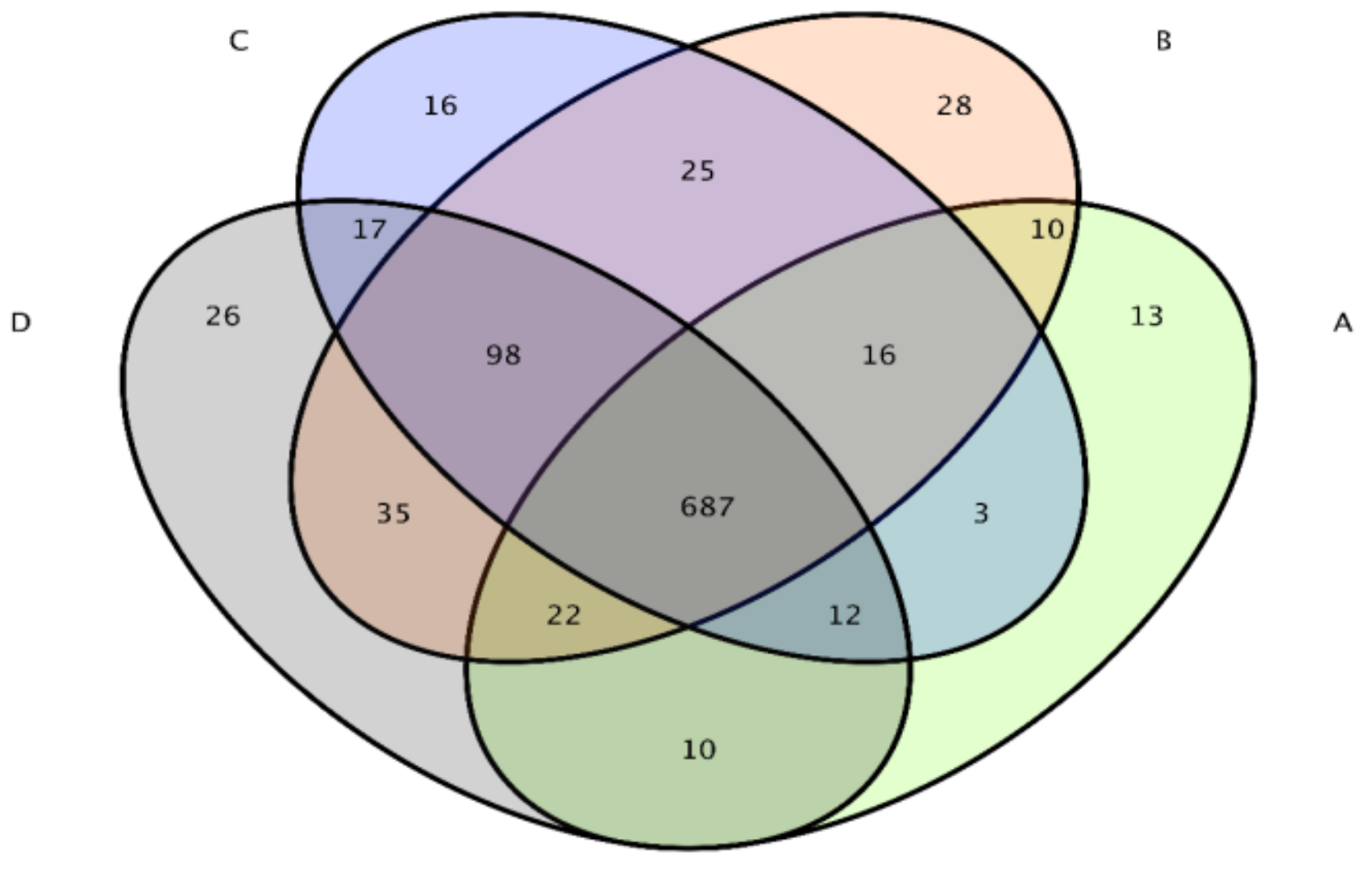

Figure 1

Ruminal fluid samples microbiota Venn diagram 


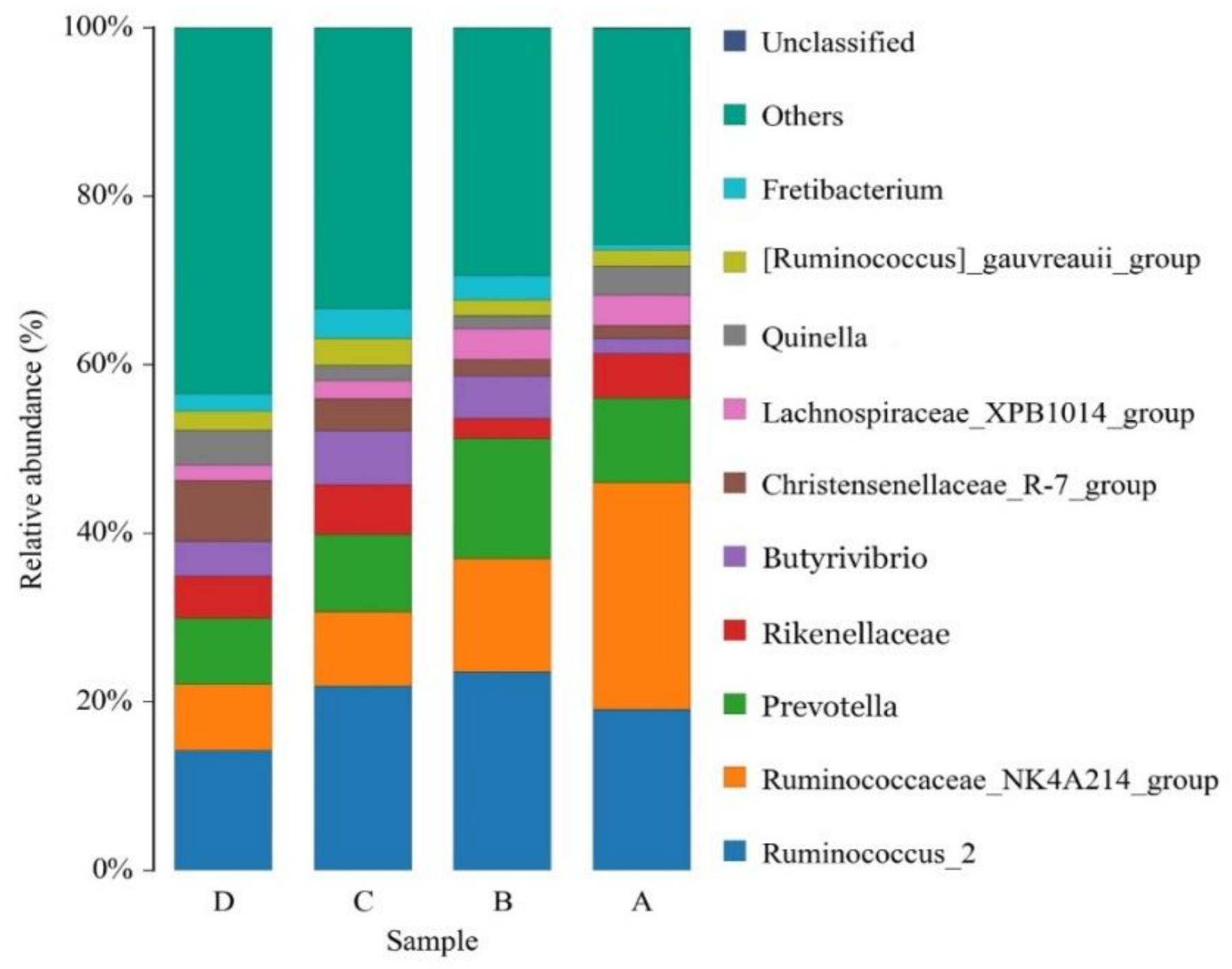

Figure 2

Percent of community abundance of microorganism 


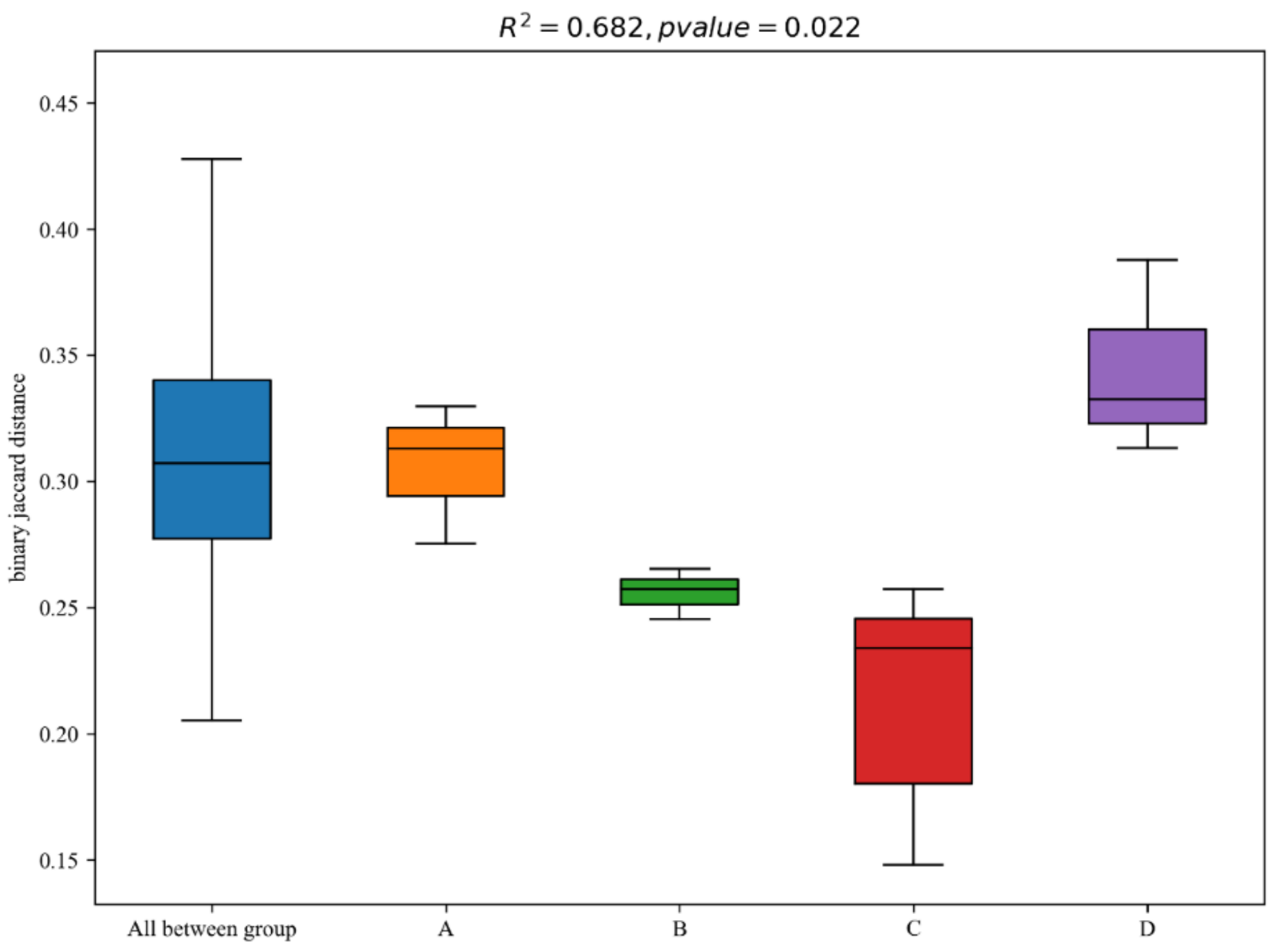

Figure 3

Ruminal fluid samples microbiota Beta-diversity Analysis 


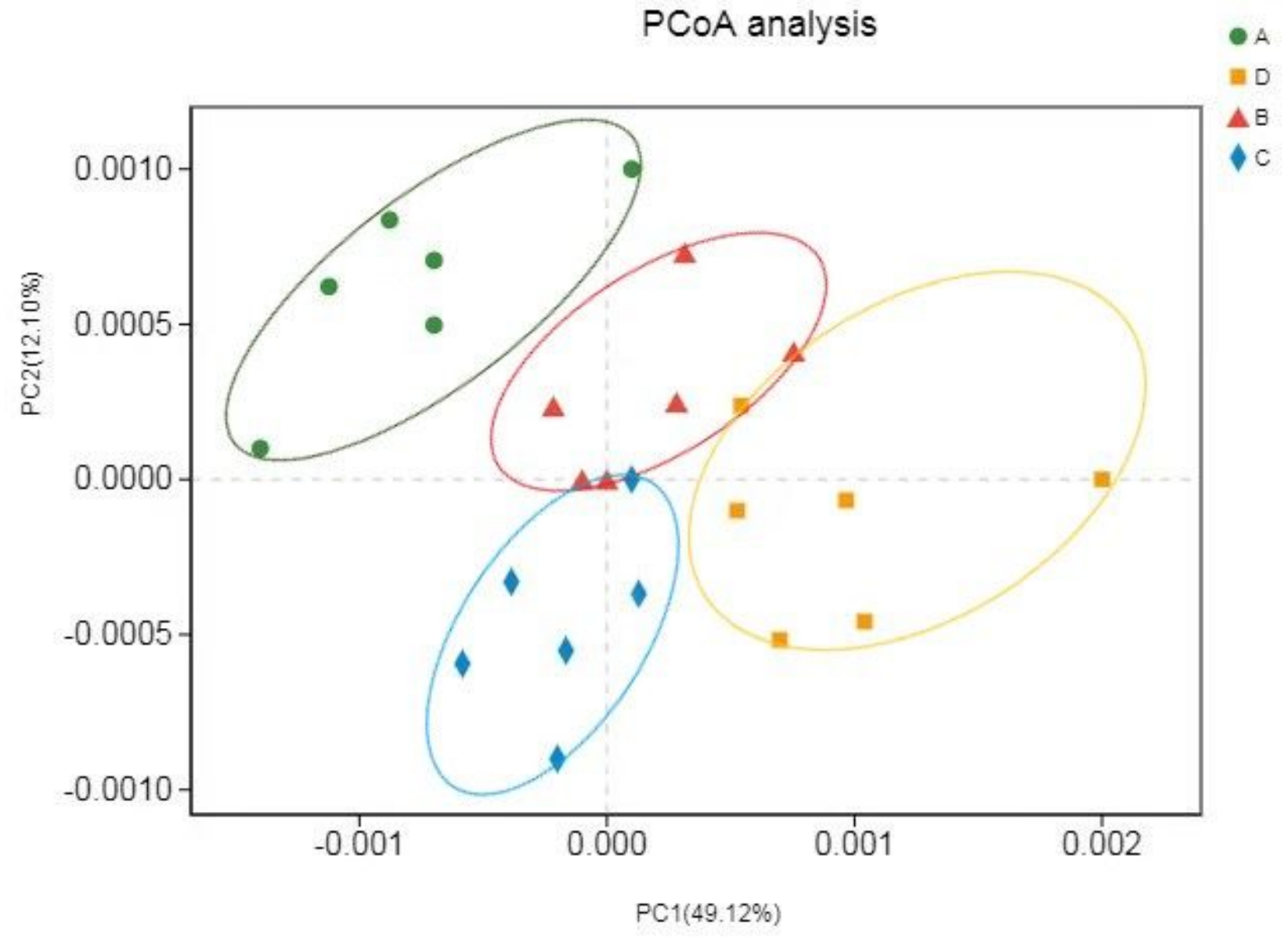

Figure 4

Ruminal fluid samples microbiota PCoA Analysis 
A

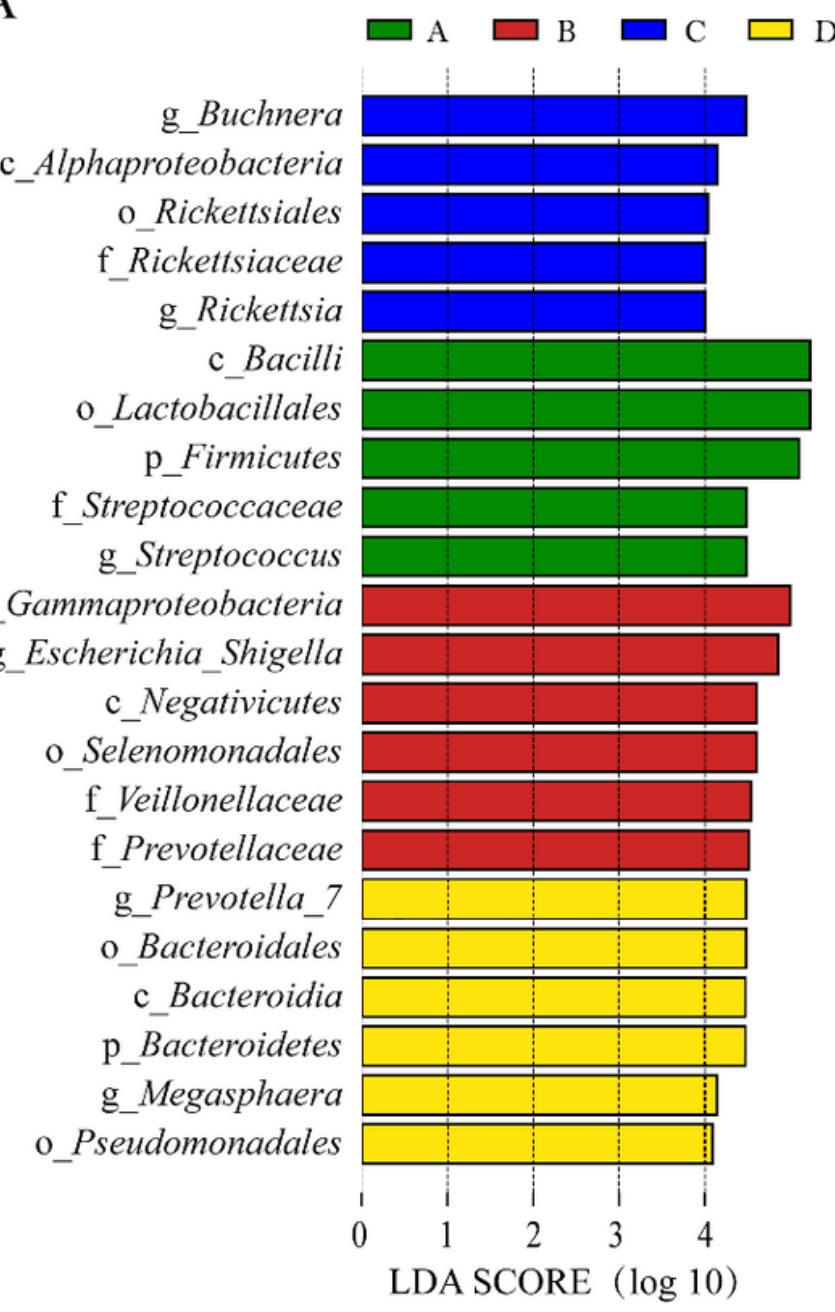

B

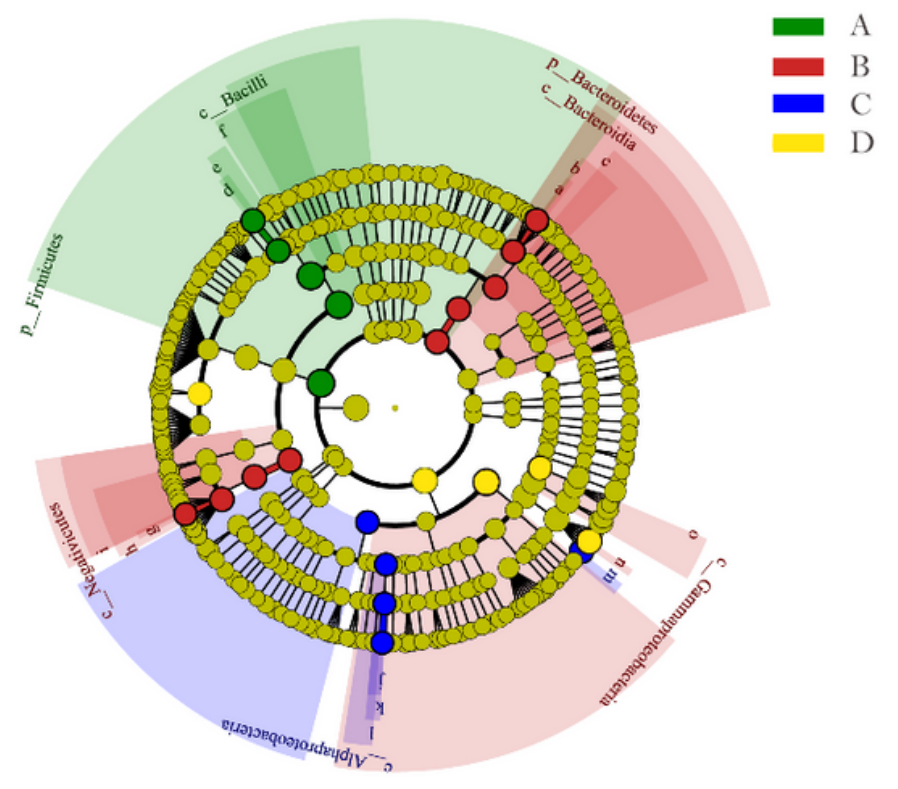

口 a: g_Prevotella_7

口 b: f_Prevotellaceae $\quad \mathrm{i}$ : o_Selenomonadales

$\square \mathrm{c}: \mathrm{o}$ B Bacteroidales

- d: g_Streptococcus

च e: f_Streptococcaceae

- f: o_Lactobacillales

口 g: g_Megasphaera

口 h: f_Veillonellaceae
- j: g_Rickettsia
- k: f_Rickettsiaceae
- 1: o_Rickettsiales
- m: g_Buchnera
口 n: g_Escherichia_Shigella
$\square$ o: o_Pseudomonadales

\section{Figure 5}

The linear discriminant analysis effect size (LEfSe) method identifies the significantly different abundant taxa of bacteria Note. B. The taxa with significantly different abundances among 4 groups were represented by colored dots, light green circles represent non-significance differences in abundance among 4 groups for that particular taxonomic group, and from the center to outward, they represent the kingdom, phylum, class, order, family, and genus levels. A: Only taxa meeting an LDA significance threshold of 4 were showed. 


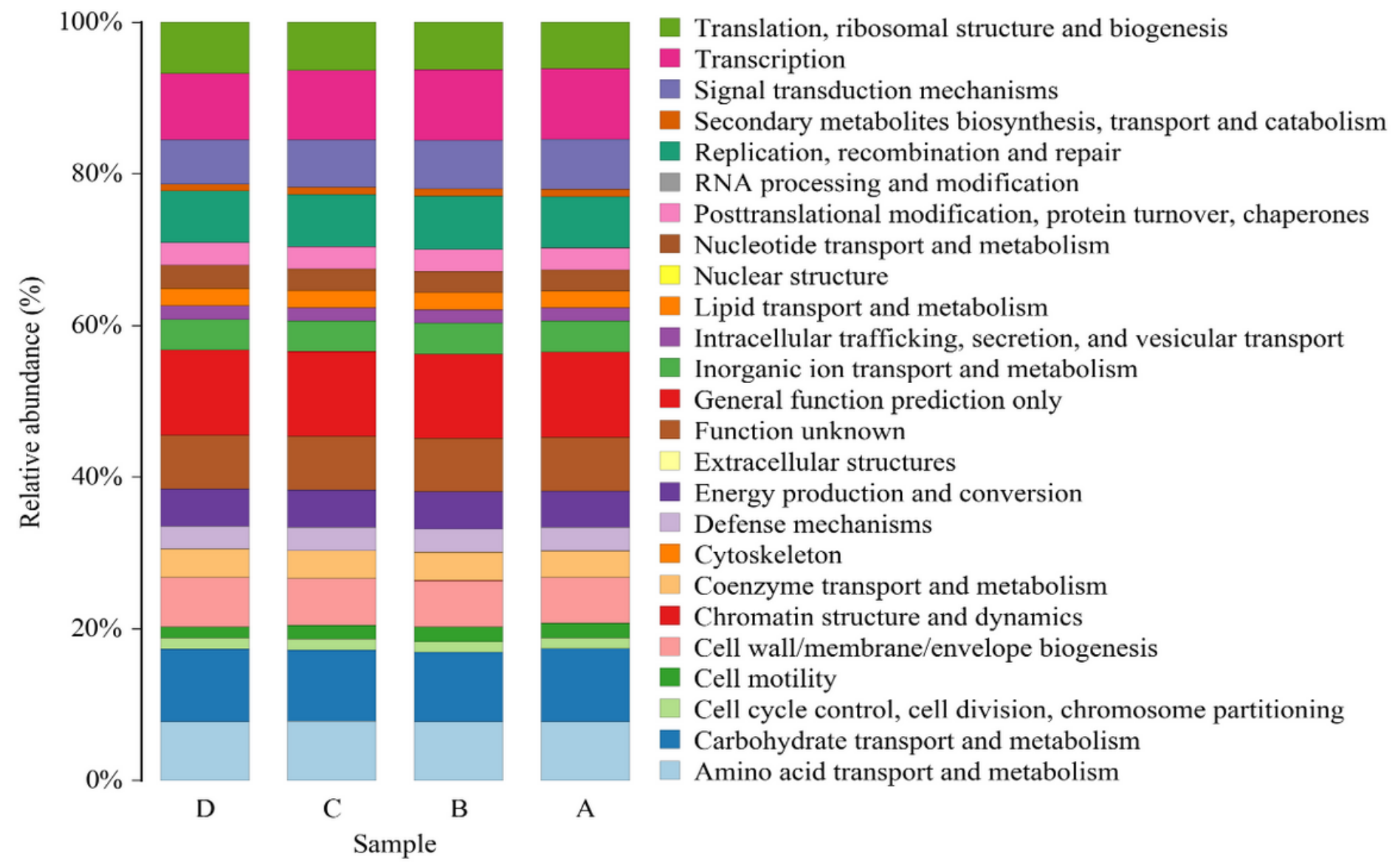

Figure 6

Ruminal fluid samples microbiota KEGG Analysis 